\title{
Serious fungal infections in the Philippines
}

\author{
M. C. R. Batac ${ }^{1}$ D. Denning ${ }^{2}$
}

Received: 21 December 2016 / Accepted: 21 December 2016/Published online: 21 February 2017

(C) The Author(s) 2017. This article is published with open access at Springerlink.com

\begin{abstract}
The Philippines is a low middle-income, tropical country in Southeast Asia. Infectious diseases remain the main causes of morbidity, including tuberculosis. AIDS/HIV prevalence is still low at $<1 \%$, but is rapidly increasing. Fungal disease surveillance has not been done, and its burden has never been estimated. This becomes more important as the population of immunocompromised patients increases, drawn from patients with AIDS, TB, malignancies, and autoimmune diseases requiring chronic steroid use. Using the methodology of the LIFE program (www.LIFE-worldwide.org), estimates were derived from data gathered from WHO, UNAIDS, Philippine Health Statistics 2011, Philippine Dermatological Society Health Information System database, HIV/AIDS and ART registry of the Philippines, epidemiological studies such as The TREAT Asia HIV Observational Database 2005, and personal communication. Aspergillosis and candidiasis were the top causes of fungal infections in the Philippines. Chronic pulmonary aspergillosis (CPA), drawn from the number of tuberculosis patients, affects 77,172 people. Allergic bronchopulmonary aspergillosis (ABPA) and severe asthma with fungal sensitization (SAFS) frequencies, which were derived from the number of asthmatic patients, affect 121,113 and 159,869 respectively. Recurrent vulvovaginal candidiasis (RVVC) affects 1,481,899 women. Other estimates were cryptococcal meningitis 84 , Pneumocystis pneumonia
\end{abstract}

\section{Denning}

ddenning@manchester.ac.uk

M. C. R. Batac

tinbatacmd@gmail.com

1 University of Manchester, Manchester, UK

2 Education and Research Center, University Hospital of South Manchester, Southmoor Road, Manchester M23 9LT, UK
391, oral candidiasis 3,467 , esophageal candidiasis 1,522 (all in HIV-infected people), invasive aspergillosis (IA) 3,085 , candidemia 1,968 , candida peritonitis 246 , mucormycosis 20 , fungal keratitis 358 , tinea capitis 846 and mycetoma 97 annually. A total of 1,852,137 (1.9\% of population) are afflicted with a serious fungal infection. Epidemiological studies are needed to validate these estimates, facilitating appropriate medical care of patients and proper prioritization of limited resources.

\section{Introduction}

In the Philippines, most of the initial epidemiological studies on mycoses focused on superficial fungal infections [1-3]. Since the 1950s, superficial mycoses have been in the top five most common diagnoses in outpatient dermatology clinics [2]. For several decades, fungal diagnostic procedures in the Philippines were not routinely done and were limited to the isolation, culture, and identification of fungi involved in skin, hair, and nail infections. Two university-based microbiology departments conduct short courses in Diagnostic Mycology on a regular basis. In the past, these used to cater solely for dermatologists, because the course was a requirement in their residency training. However, with the advent of AIDS and the compromised patient, more infectious disease fellows and medical laboratory personnel have enrolled in these courses.

The advent of AIDS, first described in the Philippines in 1984, led to a greater recognition of fatal fungal diseases [4]. Out of 470 HIV/AIDS patients seen in a tertiary general hospital in the Philippines, $32.5 \%$ presented with opportunistic infections [5]. Among the opportunistic infections, 32\% were due to Pneumocystis pneumonia, $4 \%$ to cryptococcal meningitis, and 3\% to oral thrush [5]. HIV cases are climbing steeply in the Philippines (20-30\% annual increase in the years 2013- 
2016), especially among men [4]. Patients who are on immunosuppressive agents, or are immunocompromised due to medical conditions and/or are critically ill, are also at an increased risk of acquiring serious fungal infections, and such patients are common in the urban centres of the Philippines. There is no active surveillance done for serious fungal infections in the country, and epidemiological studies even for benign superficial mycoses have been sparse. Although nationally based surveillance programs are the gold-standard in estimating disease prevalence, they are usually costly and difficult to implement [6]. Therefore, the actuarial method used by previous researchers was used in this study to estimate the incidence and prevalence of serious fungal diseases, in which results from previous epidemiological studies, populations at risk, and epidemiological databases were used [6].

\section{Methods}

Applying the methodology of the LIFE program (www.LIFEworldwide.org), prevalence and incidence of serious fungal infections were derived from data gathered from WHO, UNAIDS, Philippine Health Statistics 2011, Philippine Dermatological Society (PDS) Health Information System database, HIV/AIDS and ART registry of the Philippines, epidemiological studies such as The TREAT Asia HIV Observational Database 2005, and personal communication.

\section{Results and discussion}

\section{Population and country profile}

The Philippines is classified as lower middle income by the World Bank. It is considered one of the promising newly industrialized countries, enjoying a steady economic growth at the turn of the millennium, with a per capita 2013 gross domestic product of $\$ 2,765$. Based on the 2013 WHO statistical profile, the population of the Philippines is $98,394,000$, with $34 \%$ under the age of 15 , and $6 \%$ over the age of 60 . The median age is 23 . The number of hospital beds per population was the lowest in Asia in 2010 [7]. Table 1 shows relevant population statistics.

\section{Burden of fungal infections}

In 2016, a total of 1,852,137 severe fungal infections are estimated to have occurred in the Philippines. Table 2 shows the incidence and prevalence for selected serious fungal infections. Eighty percent of this is due to RVVC. However, local practicing obstetricians think this number is too high, and approximate that each general obstetrician sees 12-15 patients with vulvovaginal candidiasis, three to four of whom have
Table 1 Important population statistics

\begin{tabular}{lll}
\hline & Percent $^{\mathrm{a}}$ & Number \\
\hline Population (2013) & & $98,394,000$ \\
Males & 50.5 & $49,688,970$ \\
Females & 49.5 & $48,705,030$ \\
Below 15 years old & 34.0 & $33,453,960$ \\
Above 40 years old & 25.6 & $25,188,864$ \\
Above 60 years old & 6.0 & $5,903,640$ \\
Females 15-50 years old & 25.9 & $25,484,046$ \\
\hline
\end{tabular}

${ }^{a}$ (Epidemiology Bureau, Department of Health 2011)

RVVC per month. There are around 4,000 to 5,000 obstetricians in the Philippines, so the maximum estimate for the prevalence of RVVC would only be $240,000, \sim 1.2$ million less than the estimate. Those with RVVC who consult a physician do not represent everyone in the population, and many women suffer in silence. It is likely that many patients selfmedicate, since patients may purchase topical antifungals without prescription or try local remedies. Clearly, this substantial issue needs addressing in the Philippines.

HIV/AIDS cases in the Philippines are few with a cumulative number of cases at 34,999 since the first case was reported in 1984. However, a sudden rise in cases has been observed since 2009 , with $83 \%$ of cumulative cases diagnosed between 2009 to present. Most of the newly diagnosed cases are in the 25-29 age group, and among men who have sex with men $[4,8]$. Our estimated incidences of Pneumocystis pneumonia, cryptococcal meningitis, and oral candidiasis were based on HIV/AIDS cases in the recent past, which were relatively low but are increasing rapidly. Adequate diagnosis of opportunistic fungal disease with the highly sensitive and specific cryptococccal antigen lateral flow device $[9,10]$ and Pneumocystis PCR are required $[11,12]$. It is not known if disseminated histoplasmosis contributes to illness and death in AIDS in the Philippines, but it is likely. Histoplasmin reactivity has been documented, and at least nine cases of histoplasmosis have been reported $[2,13,14]$. Hand in hand with an effective AIDS prevention program and prompt and adequate treatment of cases with antiretroviral drugs, proper management of opportunistic fungal infections is required.

The Philippine prevalence of IA, CPA, ABPA, and SAFS, diseases caused by Aspergillus sp., has never been studied. However, several cases of pulmonary aspergillosis have been documented. In 1975, a case of pulmonary aspergillosis was reported in Manila in a 25-year-old male who presented with a 7-year history of hemoptysis without fever and anorexia, and who was diagnosed with tuberculosis but did not respond to anti-tuberculosis medicines [15]. From February 1982 to May 1990, 16 cases of pulmonary aspergillosis were seen at the Lung Center of 
Table 2 Prevalence and incidence of selected serious fungal infections in the Philippines, 2016

\begin{tabular}{|c|c|c|c|c|}
\hline Serious fungal infection & Estimation method & Totals & & Rate $/ 100,000$ \\
\hline Cryptococcal meningitis & $7 \%$ of new AIDS diagnosis & 84 & Annual incidence & 0.09 \\
\hline Pneumocystis pneumonia & $31 \%$ of new AIDS diagnosis & 391 & Annual incidence & 0.40 \\
\hline Invasive aspergillosis (IA) & $\begin{array}{l}10 \% \text { of } \mathrm{AML}+\text { an equal number in other } \\
\text { haematological conditions, } 0.5 \% \text { of } \\
\text { renal transplant patients, } 4 \% \text { of liver } \\
\text { transplant patients, and } 1.3 \% \text { of patients } \\
\text { hospitalized for COPD }\end{array}$ & 3,085 & Annual incidence & 3 \\
\hline Chronic pulmonary aspergillosis (CPA) & $\begin{array}{l}22 \% \text { of cavitary pulmonary TB, } 2 \% \text { of } \\
\text { non-cavitary pulmonary TB, annually, } \\
\text { reduced by } 15 \% \text { for surgery and death. }\end{array}$ & 77,172 & Prevalence & 78 \\
\hline $\begin{array}{l}\text { Allergic bronchopulmonary } \\
\text { aspergillosis (ABPA) }\end{array}$ & $2.5 \%$ of adult asthmatics & 121,113 & Prevalence & 123 \\
\hline $\begin{array}{l}\text { Severe asthma with fungal } \\
\text { sensitisation (SAFS) }\end{array}$ & $\begin{array}{l}33 \% \text { of the most severe } 10 \% \text { of adult } \\
\text { asthmatics }\end{array}$ & 159,869 & Prevalence & 162 \\
\hline Candidaemia & $\begin{array}{l}2 / 100,000 \text { general population, } 1.5 \text { in } \\
\text { non-ICU and } 0.5 \text { in ICU }\end{array}$ & 1,968 & Annual incidence & 2 \\
\hline Candida peritonitis & $50 \%$ of incidence of candidemia in ICU & 246 & Annual incidence & 0.25 \\
\hline Oral candidiasis & $\begin{array}{l}90 \% \text { of HIV patients not on antiretrovirals } \\
\text { and CD } 4<200 \times 10^{6} / \mathrm{L}\end{array}$ & 3,467 & Annual incidence & 3.5 \\
\hline Oesophageal candidiasis & $\begin{array}{l}20 \% \text { of HIV patients not on antiretrovirals and } \\
\text { CD } 4<200 \times 10^{6} / 1+5 \% \text { of HIV patients on } \\
\text { antiretrovirals }\end{array}$ & 1,522 & Annual incidence & 1.5 \\
\hline $\begin{array}{l}\text { Recurrent vulvovaginal candidiasis } \\
\text { (RVVC) ( }>4 \mathrm{x} / \text { year) }\end{array}$ & $5 \%$ of women $15-50$ years of age & $1,481,899$ & Prevalence & 3,012 \\
\hline Mucormycosis & 0.2 cases per $1,000,000$ population & 20 & Annual incidence & 0.02 \\
\hline Fungal keratitis & $\begin{array}{l}\text { Based on cases seen at a tertiary government } \\
\text { hospital in the NCR in } 2015\end{array}$ & 358 & Annual incidence & 0.36 \\
\hline Tinea capitis & $\begin{array}{l}\text { Based on cases seen at Philippine Dermatological } \\
\text { Society training institutions in } 2015\end{array}$ & 846 & Annual incidence & 0.86 \\
\hline Mycetoma & $\begin{array}{l}\text { Based on cases seen at Philippine } \\
\text { Dermatological Society training } \\
\text { institutions in } 2015\end{array}$ & 97 & Annual incidence & 0.10 \\
\hline Total serious fungal infection burden & & $1,852,137$ & & \\
\hline
\end{tabular}

the Philippines [16]. Nine of them had inactive pulmonary tuberculosis; 13 underwent lobectomy or segmentectomy or cyst removal. From Jan 2000 to December 2002, 37 patients were diagnosed with aspergilloma, and all were surgically managed. Ninety-two percent presented with hemoptysis and 95\% had tuberculosis [17]. In a retrospective study done in a private hospital in Manila, there were 14 cases of aspergillosis seen from 1998-2004; five were diabetics and three had renal transplants. Eleven presented with pulmonary aspergillosis, and three had extrapulmonary aspergillosis [18]. A case of primary laryngeal aspergillosis in a 28-year-old who presented with fever, cough, and cold a day after giving birth by caesarean section was reported [19]. The Philippines is endemic for $\mathrm{TB}$, and urban and rural areas have high rates of COPD [20]. TB and COPD are both associated with $\mathrm{CPA}$, and therefore it is probable that there are many undiagnosed CPA cases, with some of them managed as resistant TB cases. It is important to determine baseline prevalence using available serological tests.
Candidemia among infants confined in the neonatal intensive care unit was reported to affect 56 of 7,830 infants in 2004, and 31 of 7,830 infants in 2005 [21]. A case-control study done in the same facility revealed that birthweight of 1,250 to 2,499 grams and gestational age of $<28$ weeks were significantly associated with candidemia $(p<0.05)$ [21]. The rate of candidemia in different countries varied from 1.2 to 25 per 100,000 population [22]. We have decided to use two per 100,000 population since exposure to risk factors for candidemia may be low, and there are remarkably few hospitals for this populous country [7]. In some developed countries, candidemia rates are increasing instead of decreasing and may be due to increased survival of patients with severe diseases or extremely low-birth weight, more aggressive interventions in the form of surgery, transplants, invasive procedures and devices, immunosuppressive therapy, and use of broad-spectrum antibiotics [22]. These are resources that are not accessible to most Filipinos.

In 1955, dermatologists surveyed the schools where two children with tinea capitis studied; however, no additional 
case was detected. Back then, experts surmised that tinea capitis was uncommon in the Philippines and was not a public health problem, and this seems the case to this day [2]. The common dermatophytes isolated were Microsporum canis, Trichophyton tonsurans, T. mentagrophytes, and M. gypseum [2]. A total of 9,180 (11.5\% of new patients) consulted for superficial mycoses in ten PDS institutions in 2015. Fungal keratitis, tinea capitis, mycetoma, and RVVC are mycoses that affect young, productive, and otherwise healthy patients. These affect work productivity and quality of life. It is important to manage these diseases promptly to avoid complications.

The incidence of subcutaneous mycoses is rare in the Philippines, but these usually cause disfiguring lesions in young people, limiting their mobility and affecting quality of life [1]. By 1963, three patients with eumycetoma caused by Penicillium funiculosum, Madurella grisea, and Scedosporium (formerly Monosporium) apiospermum had been seen in the Philippines [23]. Eumycetoma of 20 years duration in a 40 -year-old man was found to be caused by Phialemonium sp., and was treated with terbinafine $250 \mathrm{mg}$ twice a day for 9 months followed by excision of redundant skin [24]. Another case was reported in 2009 of a 33-year-old man with draining sinuses and nodules on the left foot and thigh, from which Madurella sp. was isolated [25]. More recently, Madurella mycetomatis was cultured from the foot lesions of 9 years duration of a 33-year-old man [26]. Most of these patients were farmers. If eumycetoma presents with chronic nodules and draining sinuses, chromoblastomycosis appears as warty lesions. A few cases of chromoblastomycosis have also been reported in the Philippines, including a 58year-old man who presented with verrucous lesions of 25 years and a 71-year-old man with warty lesions of 48 years duration $[2,27]$. Both were caused by Fonsecaea compacta.

Challenges in the management of serious fungal infections in a resource-limited setting include timely diagnosis, proper antifungal intervention, patient compliance with long-term treatment, and high cost of antifungal treatment.

Acknowledgements We would like to acknowledge the help given by Dr. Vanessa de Villa (Founding Member of the Philippine Society for Transplant Surgeons and Chair of the Philippine Board of Transplant Surgery), Dr. Richard Nepomuceno (cataract, cornea, refractive surgery), Dr. Edsel Maurice T. Salvana (infectious diseases and tropical medicine, HIV/AIDS), Dr. Ricardo Manalastas (obstetrics and gynecology, infectious diseases) through Dr. Ma. Cristina Pelaez-Crisologo, Dr. Francisco Lopez (bone marrow transplant specialist) through Dr. Charina Dizon, and the Philippine Dermatological Society - Health Information Systems.

Open Access This article is distributed under the terms of the Creative Commons Attribution 4.0 International License (http:// creativecommons.org/licenses/by/4.0/), which permits unrestricted use, distribution, and reproduction in any medium, provided you give appropriate credit to the original author(s) and the source, provide a link to the Creative Commons license, and indicate if changes were made.

\section{References}

1. Handog EB, Dayrit JF (2005) Mycology in the Philippines, revisited. Jpn J Med Mycol 46:71-76. doi:10.3314/jjmm.46.71

2. Simuangco S, Bocobo F, Lacuna L (1962) Review of literature on medical mycology in the Philippines, 1955-1962. Mycopathol Mycol Appl 20:145-156. doi:10.1080/00150198808201399

3. Simuangco S (1975) Geographic dermatology: the Philippines. Acta Med Philipp 11:37-43

4. NHSS (2016) HIV/AIDS and ART registry of the Philippines (HARP). Manila

5. Salvana EM, Leyritana K, Alejandria M, Lim J, Destura R, Tenorio A (2012) Opportunistic infections in Filipino HIV patients. Abstract published and presented at the ID Week 2012 Conference on October 2012 in San Diego, CA..

6. Beardsley J, Denning DW, Chau NV, Yen NTB, Crump JA, Day JN (2015) Estimating the burden of fungal disease in Vietnam. Mycoses 58:101-106. doi:10.1111/myc.12382

7. OECD WHO (2014) Hospital care. In: Health at a Glance: Asia/ Pacific 2014. Measuring Progress towards Universal Health Coverage. OECD Publishing, Paris, pp 66-68

8. Ross AGP, Ditangco RA, Belimac JG, Olveda RM, Mercado ES, Rogers GD, Cripps AW, Lam A, Crowe SM (2013) HIV epidemic in men who have sex with men in the Philippines. Lancet Infect Dis 13:472-473. doi:10.1016/S1473-3099(13)70129-4

9. WHO (2011) Rapid advice: diagnosis, prevention and management of cryptococcal disease in HIV-infected adults, adolescents and children. World Health Organization, Geneva

10. Tang MW, Clemons K V, Katzenstein DA, Stevens DA (2015) The cryptococcal antigen lateral flow assay: A point-of-care diagnostic at an opportune time. Crit Rev Microbiol 1-9

11. Calderón EJ, Gutiérrez-Rivero S, Durand-Joly I, Dei-Cas E (2010) Pneumocystis infection in humans: diagnosis and treatment. Expert Rev Anti Infect Ther 8:683-701. doi:10.1586/eri.10.42

12. Global Action Fund for Fungal Infections (2014) GAFFI Roadmap: improving outcomes for patients with fungal infections across the world - a road map for the next decade. GAFFI, Geneva

13. Bulmer AC, Bulmer GS (2001) Incidence of histoplasmin hypersensitivity in the Philippines. Mycopathologia 149:69-71. doi:10.1023/A:1007277602576

14. Tacastacas J, Bacorro E, Berba RP, Tobias-Altura M, Sison MA, Roa F (2006) A 47 year old male with multiple ulcerated skin plaques: a case report on disseminated histoplasmosis and a review of eight previously reported cases of histoplasmosis in the Philippines. Philipp J Microbiol Infect Dis 35:5-11

15. Alora A, Alora B, Dizon G (1975) A report of a case of pulmonary aspergillosis in the Philippines. Philipp J Microbiol Infect Dis 4:46-52

16. Ramos A (1991) Pulmonary aspergillosis nine-year experience at Lung Center of the Philippines. Sci Proc 75-82

17. Castolo JP (2003) Experience in surgery for pulmonary aspergilloma. Philipp J Thorac Cardiovasc Surg 10:6-9

18. Llorin R, Chua J (2005) Aspergillosis: a case series. Int J Antimicrob Agents 26S:2005

19. Villanueva JC, Opulencia AP, Calavera KZ, Lim W (2015) Primary laryngeal aspergillosis in a postpartum patient. 30: 47-49

20. Idolor LF, De Guia TS, Francisco NA, Roa CC, Ayuyao FG, Tady CZ, Tan DT, Banal-Yang S, Balanag VM, Reyes MTN, Dantes RB (2011) Burden of obstructive lung disease in a rural setting in the Philippines. Respirology 16:1111-1118. doi:10.1111/j.14401843.2011.02027.x

21. Morales-Lagunzad NRM, Mantaring JBV (2010) Risk factors for candidemia in the neonatal intensive care unit of the Philippine 
General Hospital from October 2003 To August 2006 : a casecontrol Study. Pediatr Infect Dis Soc Philipp J 10:44-50

22. Arendrup MC (2010) Epidemiology of invasive candidiasis. Curr Opin Crit Care 16:445-452. doi:10.1097/MCC.0b013e32833e84d2

23. Reyes A (1963) A contribution to the study of mycetoma in the Philippines: maduromycosis caused by monosporium apiospermum (laboratory studies). Acta Med Philipp 19:89102

24. Abad-Venida ML, Reyes MV (2001) Eumycetoma (Phialemonium spp) cured by terbinafine. J Philipp Soc Cutan Med 8-11
25. Dela Cerna EM, Montinola F (2009) Eumycetoma in a Filipino adult man. J Philipp Dermatol Soc 18:41-43

26. Pena-Dumdum A, Banate-Gulfan G, Ledesma TG, Gabriel MT, Senador L (2016) Stage III eumycetoma successfully treated with oral ketoconazole and surgical debulking. J Philipp Dermatol Soc 25:58-61

27. Alora MBT, Bulmer GS (1993) Chromomycosis : report of a case successfully treated with itraconazole. Philipp J Microbiol Infect Dis 22:23-27

28. Epidemiology Bureau Department of Health (2011) The 2011 Philippine Health Statistics. Manila 